\title{
Under pressure: conservation choices and the threat of species extinction
}

\author{
Robin Gregory ${ }^{1,2}$ (D) Robert Kozak ${ }^{2}$ - Guillaume Peterson St-Laurent ${ }^{2,3}$. \\ Sara Nawaz ${ }^{3} \cdot$ Terre Satterfield $^{3}$. Shannon Hagerman ${ }^{2}$
}

Received: 10 September 2020 / Accepted: 19 April 2021 / Published online: 3 May 2021

(C) The Author(s), under exclusive licence to Springer Nature B.V. 2021

\begin{abstract}
Shifts in species ranges and viability introduced by climate change are creating difficult challenges for scientists and citizens. In many cases, the seriousness of threats to endangered species is forcing policy makers and resource managers to consider novel species protection strategies, either to complement or replace existing conservation approaches. This paper seeks to deepen understanding of public views on a range of conventional and novel management initiatives designed to protect species under the threat of extinction, based on results from an online survey conducted in the USA and Canada. Participants first selected a preferred intervention strategy and were then presented with a series of scenarios, focused on protection of the endangered bristlecone pine, which allowed them to explore their willingness to shift to a new policy regime with a better chance of protecting the species. The use of a decision-pathways survey design allowed us to examine the strength of the nudge required to elicit a shift in their position and the reasoning underlying selection of a preferred management alternative. Results generally support the conclusion that, so long as a clear rationale is provided, there exists surprisingly widespread support for the adoption of novel management approaches to save threatened or endangered species even if this requires more intensive genetic and transformational interventions that are costly or ethically challenging.
\end{abstract}

Keywords Climate change Endangered species $\cdot$ Adaptivemanagement $\cdot$ Surveys $\cdot$ Conservation - Public opinion

Robin Gregory

robin.gregory@ires.ubc.ca

1 Decision Research, 6054 Leaning Tree Road, Halfmoon Bay, British Columbia V0N 1Y2, Canada

2 Faculty of Forestry, University of British Columbia, 2424 Main Mall, Vancouver, British Columbia V6T 1Z4, Canada

3 Institute for Resources, Environment, and Sustainability, University of British Columbia, 2202 Main Mall, Vancouver, British Columbia V6T 1Z4, Canada 


\section{Introduction}

Conservation choices reflect both factual information and the values of individuals (Corner et al. 2014; Dietz 2013). Scientists concerned about the protection of threatened and endangered species - including conservation biologists, foresters, and wildlife ecologists - typically focus their energies on development of the most accurate information about the status of plants and animals and the effectiveness of initiatives intended to reduce threats and increase the health of critical habitats and species.

Over recent decades, however, the focus of scientists has shifted to include greater emphasis on engaging with the public and elected officials about the risks facing threatened and endangered species and the need for climate change adaptation (Boykoff 2019; Moser 2014). Communicating the urgency and complexity of climate change-driven loss is particularly salient now with recent projections suggesting that as much as one-third of species could face extinction within the next 50 years due to biodiversity loss resulting from climate change (Román-Palacios and Wiens 2020). In response, scientists, resource managers, and policy makers are actively discussing a range of interventions designed to help protect species and their preferred habitats in hopes of reducing the risks to species and ensuring their long-term survival (Heller and Zavaleta 2009; Mawdsley et al. 2009; Prober et al. 2019; Stein and Shaw 2013). The suite of policies under consideration has grown considerably in the face of concerns about the surprising speed and magnitude of climate change. Interventions that were considered radical or extreme only a short time ago (Hagerman et al. 2010), including genetic modification and a variety of assisted migration strategies, now figure prominently in discussions among leading experts (Colloff et al. 2017a; Corlett 2016; Hagerman and Satterfield 2014).

That said, research on the strength or stability of public understanding and support of these novel conservation intervention strategies in the context of climate change adaptation is nascent (Hagerman and Satterfield 2013; Peterson St-Laurent et al. 2018). Conservation strategies often require long-term funding and can place restrictions on public use of lands. Consequently, scientists are increasingly hopeful that greater public access to accurate information regarding the impending extinction of species will result in a new receptivity among citizens for innovative conservation practices. One major task facing scientists, resource managers, and policy makers is to create decision-aiding processes that help citizens understand the urgency behind more intensive conservation actions and, in turn, generate new and adaptive policies that will shift resources to better address the dire realities of at-risk species (Tam and McDaniels 2013).

This perspective is supported by psychological research on constructed preferences (Lichtenstein and Slovic 2006), which shows that, when presented with novel situations, people look to informational cues and often quickly adjust their preferences in light of new information. Conversely, beliefs held about existing risks are often strongly anchored in how a person perceives themselves and the world and may not easily shift in the face of new information (Slovic 2000). This perspective is supported by behavioural research on motivated reasoning, which suggests that people's beliefs often shape the ways in which they interpret and process new information (Dieckmann et al. 2017; Kahneman 2011); people are generally open to confirming evidence, but relatively closed to new evidence that questions their established point of view. In order to gage support for innovative policies in light of the failure of current conservation actions, citizens would, therefore, first need to accept that new and more intensive management initiatives are required, even if these involve novel actions that push the limits of what has heretofore been considered ethically acceptable. 
In light of threats to the long-term survival of many species due to climate change, this study seeks to understand the willingness of public stakeholders to revisit and adjust their support for a range of management options, including both conventional and novel initiatives (Hällfors et al. 2014). We describe results from a 2019 internet-based decision-pathways survey (Gregory et al. 1997; Gregory et al. 2016) of nearly 1500 members of the North American public which examines public perceptions of the risks and benefits associated with a range of species protection strategies by mirroring peoples' actual decision-making processes. We asked two main types of questions: what are individuals' initial preferences for management initiatives designed to protect (or not) species at risk, and what are their comfort levels in shifting to a new preferred management initiative after receiving additional information in the form of nudges of varying strength (Leonard et al. 2008)? To increase policy realism, the survey included a case study of preferred management actions with respect to the endangered Bristlecone Pine (Pinus longaeva), an iconic tree that grows exclusively in arid subalpine regions from the eastern slopes of California's Sierra Nevada mountains to the Wasatch Range in Utah (Stritch et al. 2011).

Our findings suggest that members of the public are able to understand the nature of current threats to species at risk and distinguish among the effectiveness of both conventional and novel management options. Participants respond well to the core ideas of adaptive management and, in general, show support for a more interventionist management response to avoid extinction so long as a clear rationale is provided. The results also encourage consideration of a shift in the focus of scientists, resource managers, and policy makers from the provision of information to its dissemination and communication in forms that are easily understood and can lead to more widespread understanding (Dietz 2013), and deeper consideration, of a variety of novel management strategies that support adaptive conservation initiatives.

\section{Background}

\subsection{Climate change and public assessment of risk}

Animal and plant species are becoming increasingly vulnerable to climate change. This holds true for entire ecosystems as well, where climate change impacts include, but are not limited to, shifts in temperatures, increases in the frequency and intensity of extreme weather events (e.g., droughts, storms, windthrow) and natural disturbances (e.g., insect and disease outbreaks, wildfires and flooding), changes in precipitation and water supply, and ocean acidification (Gross et al. 2016; IPCC 2014). When combined with other human activities (e.g., development, deforestation, pollution), these changes are having far-reaching consequences. Evidence suggests that $25 \%$ of species of plants and animals are already threatened and that climate change substantially increases the risk of global extinctions (IPBES 2019). It is estimated that $16-30 \%$ of a sample of 538 plant and animal species could face extinction as a direct result of climate change (Román-Palacios and Wiens 2020).

Although the factual evidence is clear, asking members of the public to answer survey questions about protecting endangered species as a result of climate change remains challenging, for several reasons: the topic is not in the normal realm of what people think about; the issues are complex and require thoughtful consideration of multiple factors; and the use of an internet survey means that responses are sought quickly and on an individual basis, as compared to a more lengthy time frame that could permit discussions with others (Fischhoff 
2007). This task is further complicated by the fact that people typically rely on two different modes of thinking when making such novel judgements (Kahneman 2011). The first, known as System 1 thinking, is fast and relies on intuition and affective responses (Slovic et al. 2002). The second, known as System 2 thinking, is slower and characterized by more thoughtful weighing of costs and benefits. Both modes of thinking are essential. However, System 1 thinking does not readily take in numeric information - the difference between a $10 \%$ and a $30 \%$ survival rate of a species does not significantly affect our System 1 response. System 2 thinking is more reflective yet can be impeded by time constraints or the initial emotional responses of System 1.

Selecting a preferred management alternative is also prone to a variety of judgmental biases that can affect how people process and weight new information (Gilovich et al. 2002). One example is the prominence effect, whereby people deal with unfamiliar choices by giving undue emphasis to one dimension of a choice (Slovic 2015). Another example is motivated reasoning, which describes peoples' tendency to take on the views of a larger social group with which they identify and subsequently cling to a position, even after contrary evidence is provided (Dieckmann et al. 2017). This judgmental bias reduces the influence of new information and can be a source of frustration for researchers and designers of environmental policies. For example, people can resist nudges based on scientific findings concerning the impacts of climate change because they interpret and subjectively weight information through the lens of their prior beliefs (Morton 2015). The resulting challenge for survey designers is learning how to present information in ways that encourage citizens to activate their more considered System 2 thinking mode and minimize the influence of more intuitive reactions, thereby creating a more informed and stable basis for the understanding and, ultimately, selection of policy alternatives to aid in climate change adaptation (Gregory et al. 2016).

\subsection{Conservation options and the role of adaptive management}

Resource managers are responsible for the protection of endangered and threatened species from a range of threats. Over recent decades, shifts in species ranges and viability induced by climate change are creating a host of challenges for resource managers (Hagerman 2016; Oliver et al. 2012; Prober et al. 2019) which, in turn, create difficult decisions for members of the public and policy makers (Aubin et al. 2011; Keenan 2015; Tam and McDaniels 2013). Strategies that involve proven, conventional methods for protecting species are often favoured by managers over novel climate-adaptive interventions (Hagerman and Pelai 2018; Hansen and Hoffman 2011; Heller and Zavaleta 2009; Peterson St-Laurent et al. In press-a). Many reasons explain this preference for conventional interventions, including greater familiarity with conventional approaches to conservation (Sousa-Silva et al. 2016), a higher comfort level with ethical and value-based judgements (Meine 2015; Miller et al. 2014), and worries about the risks associated with new interventions (Dumroese et al. 2015; Park and Talbot 2012). Conventional interventions designed to deal with climate change are also less likely to lead to either political or social upheaval and opposition (Garnett et al. 2018; Peterson St-Laurent et al. 2018; Tam and McDaniels 2013), presumably an important consideration for many managers, to the extent that they prefer strategies that are broadly supported and can readily be implemented.

However, the profound threats introduced by climate change are forcing managers out of their comfort zones and, in many cases, requiring them to consider novel species protection strategies addressing plants (e.g., whitebark pine; Palmer and Larson 2014) or animals (e.g., 
woodland caribou; Serrouya et al. 2019), either as a complement to or as a replacement for more familiar methods. Many traditional interventions focus either on maintaining historical or current conditions or increasing the capacity of a system to return to its previous conditions after a disturbance (Hagerman et al. 2010; Heller and Zavaleta 2009). However, the unprecedented changes in climate (IPCC 2018) and biodiversity loss (IPBES 2019) are encouraging a paradigm shift in the conservation community which recognizes that future management of ecosystems will need to at least consider novel interventions that include a certain degree of transformation (Colloff et al. 2017a; Millar et al. 2007; Peterson St-Laurent et al. In press-b; Stein and Shaw 2013).

This reframing introduces a range of new, transformative options (Hobbs et al. 2009). Assisted migration, which refers to the human-assisted movement of species or populations into new areas (within or outside of native range) anticipated to be more climatically suitable in the future based on climate projections and genomic information, has been proposed to prevent species extinction or maintain ecosystems' functionalities (Hällfors et al. 2014; HoeghGuldberg et al. 2008). Another approach, known as objective setting by triage (Bottrill et al. 2008), involves the prioritization of species with the greatest potential to be conserved instead of focusing on the most endangered. This implies that the extinction of endangered species with low chances of survival is judged acceptable in order to optimize overall conservation outcomes (e.g., maintaining overall ecosystem functionalities).

Such novel climate-adaptive options are not without controversy, due to the ethical issues and ecological risks to which they give rise. For instance, assisted migration involves concerns regarding the transgression of natural boundaries (Aubin et al. 2011; Hancock and Gallagher 2014; Peterson St-Laurent et al. 2018) and may contribute to the introduction of invasive species, pests, or diseases (Dumroese et al. 2015; Park and Talbot 2012; Pedlar et al. 2012). Objective setting by triage also raises moral issues in terms of deciding which species are conserved, how these decisions are made, and by whom (Bottrill et al. 2008; Knight et al. 2019). Because of the risks and values-based thresholds inherent in these more interventionist management responses, segments of the public as well as experts may prefer to rely on status quo or business-as-usual conservation strategies, at times favouring non-interventionist policies that step back and let nature take its course (Hagerman and Satterfield 2014).

Adaptive management could provide a helpful decision framework for testing and implementing climate-adaptive options within the conservation sciences. The concept is widely employed by environmental managers when there is uncertainty about how best to approach a problem (Folke et al. 2005), such as protecting an endangered species. It refers to policy designs that help resource managers closely monitor the response of ecological systems and adjust their actions based on what is learned (Walters 1986). Although the concept has been applied widely to ecosystem problems with varying urgencies and spatial scales, results to date have been mixed (Walters 1997). This is due, in part, to institutional and temporal challenges (i.e., is the management system sufficiently flexible to adapt, and to do so rapidly enough based on what is learned?) but also to a lack of citizen support for the longer time frames and, in many cases, higher costs and perceptions of greater risks associated with adaptive management programs (Gregory et al. 2006; Walters 1997).

Public support for adaptive responses to the management of endangered species requires a willingness to consider different objectives and strategies based on the results of new information about the rate of change in underlying conditions (e.g., related to climate change), the effectiveness of different programs (e.g., their near-term ability to reduce extinction risks), and/ or the influence of conservation initiatives on other concerns (e.g., economics or society) 
(Failing et al. 2013; Gregory et al. 2013). The evidence for public willingness to accept changes in management strategies as a response to threats posed by climate change is mixed (Shrum et al. 2020, in press). The prevalence of increasingly polarized views in current-day North America suggests a reluctance to be adaptive, whereas the novelty of the choices pushed forward by climate change suggests that people might be unusually open to nudges in the form of new information regarding the benefits, costs, and consequences of different strategies. The challenge facing scientists, resource managers, and policy makers interested in exploring adaptive approaches to the protection of endangered species revolves around the provision of information about the performance of different strategies in ways that people's thinking remains flexible and open to this new information.

\section{Methods}

\subsection{Survey design}

Asking questions of people that concern novel initiatives, such as interventions in natural functioning of ecosystems to reduce the risks facing threatened and endangered species, imposes important requirements on survey designers for two primary reasons: (1) people's understanding of both actions and consequences is likely to be low; and (2) there may exist strong ethical discomfort, at least for some people, with respect to actions by humans that potentially interfere with nature. These qualities suggest that opinions about a range of novel interventions to protect species-at-risk are likely to be unformed, and, therefore, requiring additional information as part of an "upstream engagement" seeking to inform scientists, resource managers, and policy makers. These conditions differ from the usual assumptions for surveys because the public-at-large may lack important information or may not have thought sufficiently about the topic to be able to express clear and relatively stable responses.

Decision-pathway surveys (Gregory et al. 1997) represent a potentially helpful approach to incorporating public input because, rather than quickly focusing on outcomes ("would you support policy A, yes or no?"), they seek to provide information about the background context that contributes to shaping an individual's opinions (e.g., their political beliefs) and on helping people to understand trade-offs that might inform their own reasoning processes. This perspective is based in the behavioural decisions finding that preferences are often built, rather than simply revealed, in the course of an elicitation procedure (Gregory et al. 1993). This means that an active process of preference construction is underway-consciously or notwhenever a survey asks people to connect with their values and select a specific management action (Satterfield and Gregory 1998).

A related survey design consideration is that the questions asked of participants must be cognitively appropriate, with language clearly explained. People need to feel they are sufficiently well informed to answer the questions asked of them, yet not overwhelmed with unnecessary detail. Decision-pathway surveys represent one analytic technique to quantify these behavioural realities; the current survey builds on previous applications to forest management problems (Gregory et al. 1997), understanding public responses to climate change policies (Gregory et al. 2016), and other environmental and technological issues (Satterfield et al. 2012).

With these considerations in mind, we used an online decision-pathway survey to explore the views of the general public in Canada and the USA regarding a range of forest 
management interventions designed to reduce the risks to threatened and endangered species (the survey questionnaire is available in Online Resource 1). This study focused on the role of climate change and used the endangered bristlecone pine as a case study. The survey comprised 33 questions including multiple-choice questions, rating questions using continuous interval and Likert scales, and open-ended questions. Other aspects of the survey, specifically as relate to shifting comfort levels with forest interventions more broadly, are forthcoming in a separate paper.

We first presented respondents with a short initial description of the survey context and then asked them to indicate whether, in principle, they were comfortable, not comfortable, or uncertain about intervening in forest ecosystems as a result of changes brought on by climate change. We followed with questions to help us understand their reasoning and asked whether their views on a preferred management strategy would change if unanticipated outcomes were to take place. The next section of the survey briefly introduced the case of the bristlecone pine, focusing on its ecological, cultural, and economic values and its unique status as one of the oldest tree species in North America. We explained that the future survival of the species is in doubt because climate change is forcing bristlecone pines to shift so far upslope that they have "nowhere left to go." We then asked respondents their views on which of four possible management approaches identified by experts (including scientists, ethicists, foresters, and community representatives) should take priority. The four management approaches were arranged on a continuum, from least to most interventionist:

1. Non-intervention: Let nature take its course by accepting inevitable changes already underway (e.g., new species moving in, and the potential for extinction of bristlecone pine)

2. Conventional intervention: Promote the survival of bristlecone pine by planting bristlecone seedlings and adding shade structures (e.g., stumps, boulders, logs)

3. Active intervention: Help bristlecone pines survive by introducing only those bristlecone pines that have genetic traits most needed for survival

4. Transformative intervention: Accept that bristlecone pines are unlikely to survive, and therefore introduce pine species from other high-altitude terrain expected to do well in bristlecone areas

In the next section, we explored whether the provision of additional information shifted respondents' initial views regarding the management of the bristlecone pines. First, we used a 5-point continuous interval scale to inquire whether respondents would be in favour of more intensive interventions if they were to learn from experts that (1) bristlecone loss has been faster than expected (for those initially selecting non-intervention or conventional intervention) or the new bristlecone pines failed to establish (for the other two groups); (2) the economic and social benefits provided by bristlecone-related tourism and recreation are dropping; (3) bristlecone ability to adapt to natural disturbances such as droughts is decreasing; and (4) the impact of climate change on bristlecone pines is more severe than projected. Second, we asked respondents to indicate which of the four previously introduced management approaches they would prefer if, after ten years of close monitoring, results indicated that the bristlecone pine population was either "doing well" or "definitely failing." Each respondent answered the question for only one of the two scenarios: half of the sample received the prompt that the bristlecone pine population was "doing well" and the other half that it was "definitely failing". 
In the final section of the survey, we asked demographic questions (gender, age, region of residence), as well as questions about respondents' level of education and political views, hypothesizing that these factors might help to explain differences among responses. We also asked respondents to indicate, using 5-point continuous interval scales, their perceived importance conferred to (1) bristlecone pines; (2) forest ecosystems in general; and (3) problems associated with forest ecosystems as compared to other environmental or social problems. We created a numerical index (the "perceived importance of forests index") by averaging respondents' scores to these three questions. At the end of the survey, participants were thanked an encouraged to contact the survey leads if they had any questions.

\subsection{Data collection and analysis}

We used Qualtrics software (https://www.qualtrics.com) to create an online version of the survey. We distributed the survey between May 1 and June 3, 2019, to adults over the age of 18 living in the USA and Canada. The sampling was carried out by a digital data collection company (Dynata, https://www.dynata.com) and was stratified demographically (age, race, and gender) by state/province. We initially piloted the survey with a sample of $n=40$, after which we made several small formatting and wording revisions. To achieve the final sample frame $(n=1490)$, we removed incomplete responses and those that were completed in less than $5 \mathrm{~min}$. Of the responses analysed, participants took an average of roughly $15 \mathrm{~min}$ to complete the survey.

All statistical analyses were conducted in R Studio (version 1.2.1335) using descriptive statistics (e.g., means, frequencies) to summarize the different variables used in the study. We compared proportionate responses using a Z-test of the difference between two proportions. Binomial logistic regressions then were used to assess the effects of demographics and the perceived importance of forest index on preference for management approaches.

\section{Results}

The principle aims of this study were to understand individuals' initial preferences for forest management strategies to protect species at risk and to see how their policy preferences and comfort levels shifted after receiving additional information. A breakdown of survey respondents' initial comfort levels is shown in Fig. 1. Following from the decision-pathways design, responses to interventions in forest ecosystems showed a 3-way split: people were either comfortable with intervening (because climate change effects are so severe that it's time to start thinking about redesigning nature), not comfortable (because intervening feels like redesigning nature and is a slippery slope), or uncertain (because interventions and redesigning nature cross an unacceptable line). As shown in Fig. 1, a large majority of respondents were either comfortable $(46 \%)$ or uncertain $(41 \%)$ with intervening in forest ecosystems as a means of addressing climate change.

Response patterns for the uncomfortable minority (13\%) were similar to the uncertain group. This is demonstrated by the lesser preference of uncertain and uncomfortable respondents for the higher levels of intervention (active and transformative) in the context of strategies to protect endangered bristlecone pines. The leap from active interventions, involving the introduction of genetic material from successful pines, to transformative, which involves the introduction of non-local pine species, is likely responsible for the relatively 


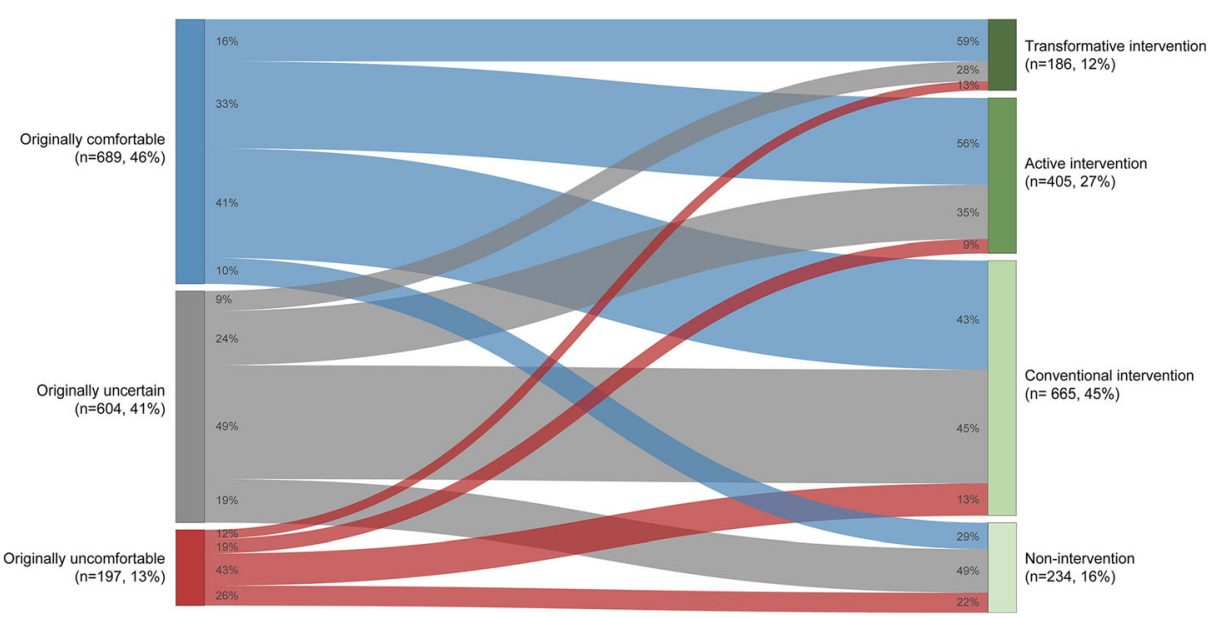

Fig. 1 Sankey diagram showing the proportion of respondents' preferred management approaches for Bristlecone pine interventions based on their levels of comfort about intervening in forest ecosystems, given climate change

small numbers of participants favouring transformative management strategies. In contrast, the comfortable group was more likely to prefer higher levels of management interventions. Those respondents more comfortable with, or uncertain about, intervening also were less likely to support a do-nothing approach of non-intervention, which was the second option most often favoured by the uncomfortable group after conventional intervention.

For each level of intervention, a binomial logistic regression was conducted to ascertain the importance ascribed to a number of demographic and psychographic variables in determining survey respondents' levels of support (Table 1). The only variable that was significant across all interventions was political views. Respondents with more conservative leanings (based on participants' self-ratings) were more likely to support lower levels of intervention (nonintervention and conventional), while respondents with more liberal political views were more likely to support higher levels of intervention (active and transformative). We also noted a gender effect for these lower levels of interventions, with males being more likely to support

Table 1 Binomial logistic regressions for determinants of preferred interventions $(n=1418)$. Beta coefficient and odds ratio (in parenthesis) are shown

\begin{tabular}{lllll}
\hline & Non-intervention & Conventional & Active & Transformative \\
\hline Perceived importance of forests index $-0.63(0.53) * * *$ & $-0.01(0.99)$ & $0.42(1.52) * * *$ & $0.15(1.16) *$ \\
Gender (male) $^{1}$ & $0.35(1.42) *$ & $-0.29(0.75) * *$ & $0.03(1.03)$ & $0.24(1.27)$ \\
Age & $0.01(1.01)$ & $-0.01(0.99)$ & $0.01(1.01)$ & $-0.01(0.99)$ \\
Country of residence: USA ${ }^{2}$ & $0.17(1.18)$ & $0.11(1.12)$ & $-0.09(0.92)$ & $-0.30 *(0.74)$ \\
Education & $0.02(1.02)$ & $-0.03(0.97)$ & $0.06(1.06)$ & $-0.04(0.96)$ \\
Political: liberal & $-0.41 *(0.66)$ & $-0.20(0.82)$ & $0.41(1.51) * *$ & $0.05(1.05)$ \\
Political: conservative & $0.25(1.29)$ & $-0.03(0.97)$ & $-0.11(0.89)$ & $-0.16(0.86)$ \\
Political: Centrist & NA & NA & NA & NA \\
Nagelkerke R2 & 0.12 & 0.02 & 0.07 & 0.02 \\
Classification table: percentage correct & 0.85 & 0.56 & 0.73 & 0.89 \\
\hline
\end{tabular}

$* p \leq 0.05 ; * * p<0.01 ; * * * p<0.001$

1. The baseline for gender was female

2. The baseline for country of residence was Canada 
non-intervention and females being more likely to support conventional intervention. Country of residence was a significant discriminating variable only for one management option, with the approximately 900 Americans in our sample less likely on average to support transformative strategies than the approximately 600 Canadians. Finally, the degree to which Bristlecone pines were important to respondents also played a role in respondents' levels of support. Not surprisingly, those who did not assign a great deal of importance to Bristlecone pines were more likely to support doing nothing, while those who did were more likely to opt for an active intervention.

We were also interested in testing the degree to which participants' choices were labile after exposure to different information concerning the effectiveness of conservation interventions, the influence of policies on economic or social concerns, and the strength of climate change impacts. Specifically, respondents from each of the four management intervention groups were provided with one of four different message frames and then asked about the degree to which they would intervene further. As shown in Fig. 2, these four frames stated (1) either that losses are faster than expected or new bristlecone pines failed to establish; (2) economic and social benefits are decreasing; (3) resilience (defined in terms of the bristlecone pine's response to natural disturbances such as droughts) is decreasing; and (4) climate change impacts are more severe than projected. Proportional results are plotted with means and standard errors (based on scores ranging from $-2=I$ would definitely not intervene further to $+2=I$ would definitely intervene further) tabulated below.

The first notable trend is the consistency of the two extreme groups (i.e., I would probably intervene further vs. I would definitely not intervene further). Approximately half of the respondents who initially preferred non-intervention stated that they would probably/ definitely not intervene further irrespective of the message framing around Bristlecone pine. The same response pattern was observed for the group originally preferring transformative

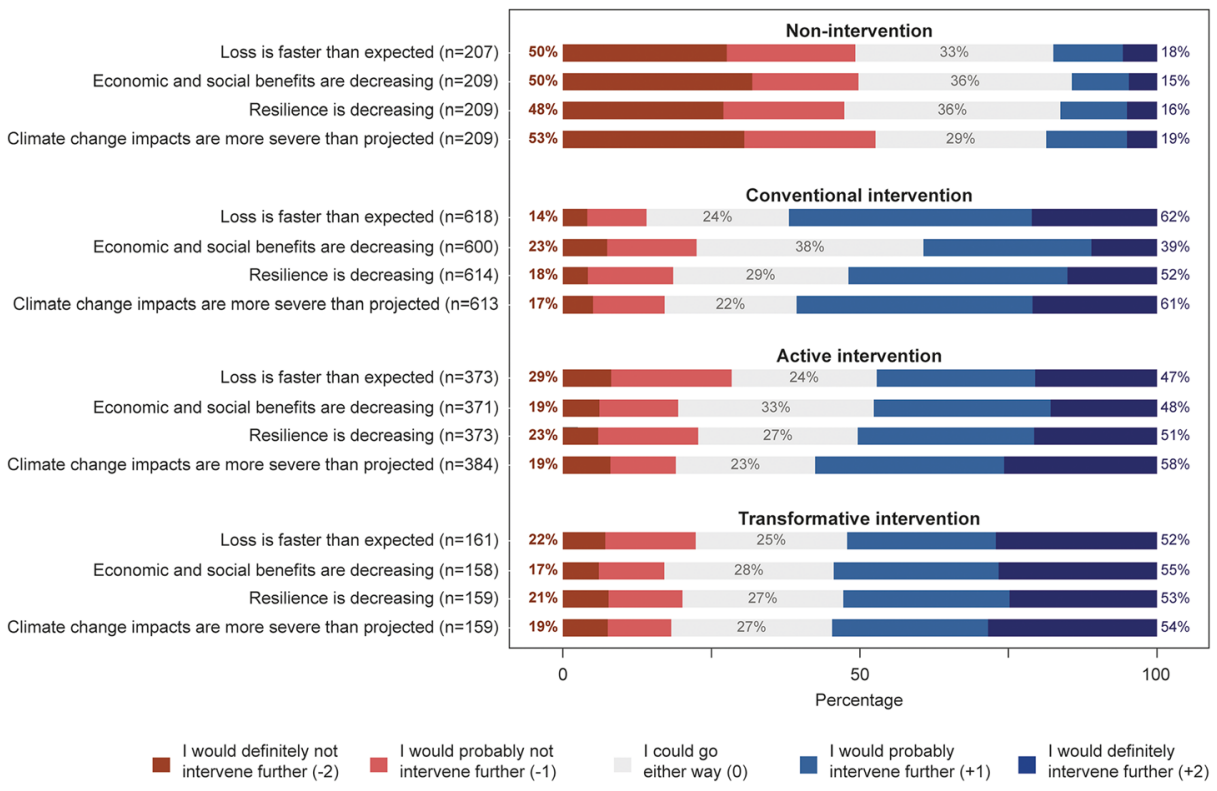

Fig. 2 Proportion of respondents who would or would not intervene further after being presented with four new concerns about the Bristlecone pine, grouped by their initially preferred management options 
intervention, except in reverse. Here, approximately half of the respondents would definitely/ probably intervene even further under any circumstance. The response patterns for these two groups were distinct from the respondents in the other two more moderate management strategies, which (not surprisingly) fell in between the two extremes with respect to willingness to intervene further after being presented with additional information about the Bristlecone pine.

Malleability was tested in terms of the impacts of different messaging frames on the stability of initial expressions of management preferences. For the group that initially preferred conventional intervention, messaging about the rate of climate change impacts and the severity of impacts was more effective than messaging about resilience with respect to participants' willingness to intervene further. For the group that initially preferred active intervention, messaging about the severity of climate change impacts had a significantly higher influence in swaying respondents to intervene further than messaging about the rate of loss. Interestingly, messaging about the negative effects of conservation options on economic and social benefits was not as impactful as the other frames, although the influence of this sort of messaging increased with the degree of intervention: respondents who initially preferred transformative intervention were more strongly influenced by declines in economic and social benefits than those who initially preferred conventional intervention or no intervention at all.

Because the outcomes associated with species conservation policies often do not become clear for at least a decade, respondents were also provided with positive and negative frames that projected results of management interventions 10 years into the future. Specifically, respondents who had earlier self-selected into one of the four management intervention groups were asked whether they would consider shifting to a different intervention strategy if, after 10 years of close monitoring, Bristlecone pines were either "now doing well" or were "definitely failing" (randomly assigned). Results are shown broadly in Fig. 3 (proportions of respondents who either preferred the same or a different management intervention) and more

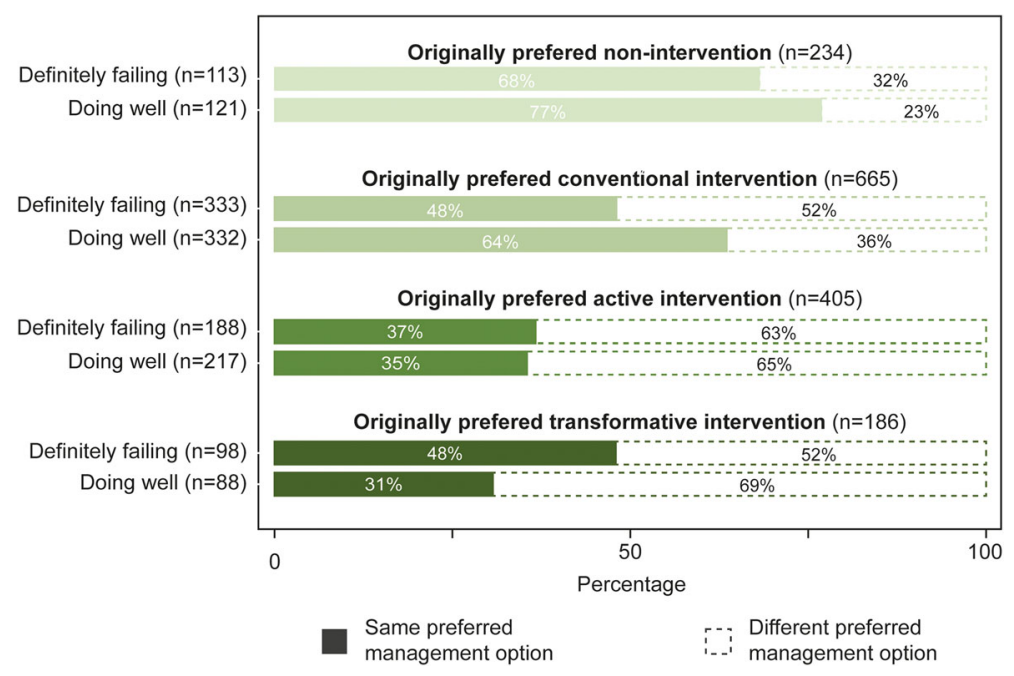

Fig. 3 Proportion of respondents who preferred the same or a different management option after learning that results from 10 years of monitoring indicated that the Bristlecone pine population was now either doing well or definitely failing, grouped by their initially preferred management interventions 
precisely in Fig. 4 (proportions of respondents who preferred specific management interventions according to their comfort levels in intervening with forest ecosystems).

Figure 3, which tracks each respondent's changes, shows that respondents who originally preferred non-intervention were the least likely to opt for another management option,

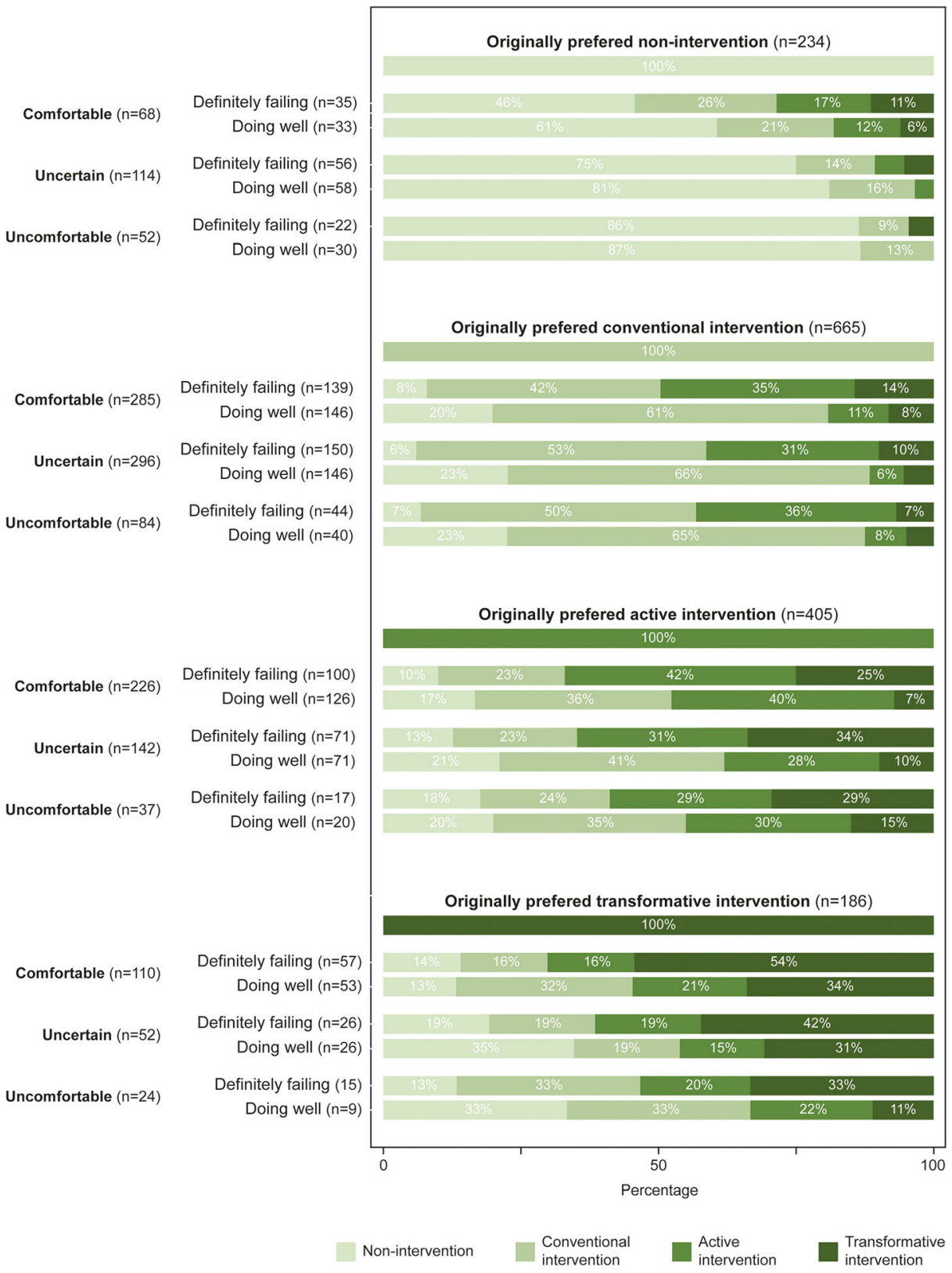

Fig. 4 Based on their initial comfort levels with intervening in forest ecosystems and originally preferred management options (see Fig. 3), respondents' preferred managements options after learning whether 10 years of monitoring indicated that the bristlecone pine population was now either doing well or definitely failing 
followed by those who initially preferred conventional interventions. Those respondents who favoured the two more technology-intensive management options - active and, to a lesser extent, transformative interventions - were more labile and willing to explore alternative strategies. The proportion of respondents willing to change their minds also varied when confronted with either a positive or a negative frame. For those who initially preferred conventional interventions, the negative frame was significantly more influential (Z-test of two proportions at $\alpha=0.05, p<0.00001$ ), whereas for those who preferred transformative interventions, the opposite was true: a positive framing of the future outcome had significantly more influence (Z-test of two proportions at $\alpha=0.05, p<0.05$ ).

Figure 4 in order to better understand how respondents might react to the implementation of adaptive management policies, we also report an additional level of detail in the decisionpathway survey results that shows, for each initial level of comfort, shifts in respondents' choice of preferred management intervention in light of either positive or negative results from a decade of monitoring (Fig. 4). Respondents who originally preferred non-intervention as a management approach $(n=234)$ were the least flexible group with respect to a willingness to shift to other management strategies. This lack of flexibility was also observed, although to a lesser extent, for the conventional and transformative intervention groups. The group that originally was most comfortable with active interventions in forest ecosystems also was the most willing to shift management approaches after receiving the monitoring results.

For those respondents who originally preferred non-intervention, the willingness to support more proactive interventions decreased in line with their comfort level. In addition, the relative influence of negative messaging (compared to positive messaging) decreased with reduced levels of comfort. The opposite was true for those respondents who originally preferred transformative interventions: as the comfort levels of respondents decrease, they become more willing to explore other interventions. For respondents who originally preferred the two interventions at the centre of the continuum, the results are more ambiguous. That said, those respondents who originally preferred active interventions showed a higher willingness to explore other interventions than those in the conventional group.

\section{Discussion}

This paper seeks to deepen understanding of public views on initiatives designed to protect species under the threat of extinction due to climate change and the degree to which preferences for management policies are adaptive in light of new information. We conducted an online survey in the USA and Canada that investigated public willingness to support the implementation of a range of conventional and novel management strategies intended to protect the iconic bristlecone pine, an endangered species. The use of a decision-pathways survey design allowed us to introduce weaker or stronger nudges and then ask participants their willingness to shift to a new policy with a better chance of protecting the endangered species. Responses reflect an individual's comfort level with their initial policy choice, their willingness to be adaptive and to act on new information about the success of an action, and the strength of the nudge required to elicit a shift in their positions.

Our results generally extend the understanding of conservation interventions in the face of threats from climate change (Hansen and Hoffman 2011). They support the view that there is likely to be a relatively high tolerance for interventions that seek to save many threatened or endangered species: when asked about the bristlecone pine, over $80 \%$ of respondents were 
willing to support at least some degree of intervention and more than one-third opted for new, more intensive conservation strategies (i.e., active and transformative interventions) to help adapt to threats from climate change. These results contrast with those of several previous studies which suggest a non-intervening, "don't mess with nature" position would receive higher levels of support (Corner et al. 2013; Hagerman et al. 2010; Kohl et al. 2019).

Figure 5 conceptualizes our interpretation of the reasoning behind our respondents' preferences for management options based on the convergence of two desired objectives: (1) the conservation of the bristlecone pine (y-axis) and (2) climate change adaptation through interventions in natural ecosystems (x-axis). Conventional intervention, which represents business as usual, is used as a baseline for both axes. Figure 5 also illustrates the proportions of respondent who indicated being comfortable with intervening in forest ecosystems out of the total number of respondents who preferred each management option. It suggests a potential categorization of individuals into three main groups: (1) those who prefer not to intervene at all in forest ecosystems (i.e., non-intervention); (2) those who prefer some form of intervention because they value the conservation of an endangered species (i.e., conventional and active intervention); and (3) those who believe it is more important to maintain ecosystem functionalities than to preserve individual species (i.e., transformative intervention).

Demographic and social characteristics, such as socio-economic status, education, gender, and ethnicity, often represent significant determinants of how risks are perceived and decisions are made (Brest and Krieger 2010). In our study of preferences for conservation options, respondents initially favouring non-intervention (16\%) were more likely to be male. Those selecting non-intervention may perceive lower levels of associated risks, a characteristic other

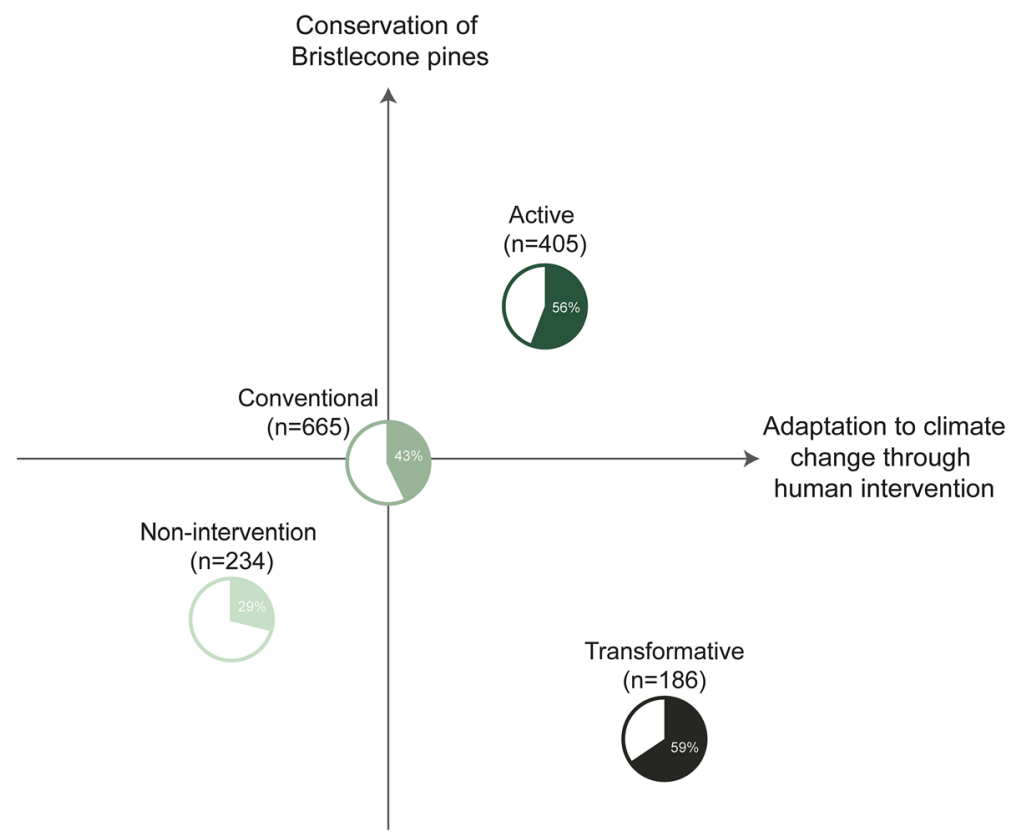

Fig. 5 Conceptual interpretation illustrating the relative degree of preference for the four management options in pursuing the dual objectives of conserving bristlecone pines (y-axis) and adapting to climate change through human intervention (x-axis). Each management option is represented with a pie chart showing the proportion of respondents who were also initially comfortable with intervening in forest ecosystems in light of climate change out of the total number of respondents (n) preferring that management option 
studies have associated with male respondents; these same individuals might also be less likely to act on a range of environmental issues (Flynn et al. 1994; Kahan et al. 2007). While we did not explore the effect of race or ethnicity in this study, previous studies also highlight the "white male effect," which suggests that for many sources of risk white males are likely to have lower-risk perceptions (Slovic 1997). This demographic group is also more likely to be conservative (Flynn et al. 1994), which may explain why a liberal orientation had an opposite effect in our regression (i.e., less likely to support non-intervention). In addition, previous studies have shown that politically liberal individuals and women are generally more willing to support biodiversity conservation (Steel et al. 1994), which may, in part, explain their lower levels of support for non-interventionist conservation approaches designed to deal with climate change.

Respondents who favoured non-intervention (in the lower left quadrant of Fig. 5) advocate for little in the way of anthropogenic actions, a fact that is reflected in the low proportion (29\%) who are comfortable with intervening in forest ecosystems. This segment of respondents also believes that less effort - at least compared to what is currently viable in the form of conventional interventions - should be devoted to the conservation of bristlecone pine. Even after being told that 10 years on policies were not working well, $77 \%$ of respondents chose to stay with a non-interventionist approach. Thus, it can be concluded that this segment is generally unwilling to support an adaptive approach to management, reflecting the view that nature is best protected if left alone (Kohl et al. 2019). That said, in the context of ecosystem management, non-intervention could also be perceived as the riskiest option because it does nothing to help ecosystems adapt to climate change, a choice that is at odds with the scientific community and the increasing importance placed on the need for adaptation (Colloff et al. 2017b; Heller and Hobbs 2014; Hobbs et al. 2009; Kareiva and Fuller 2016).

The largest group of respondents in our survey (45\%) favoured conventional means of climate-responsive intervention (at the centre Fig. 5), such as promoting the survival of bristlecone pine by using a business-as-usual approach (e.g., planting seedlings and adding shade structures). These individuals tended to prefer staying with well-known management initiatives and showed a low tolerance for changing strategies or taking on new technological risks. Many participants in this group expressed uncertainty or discomfort about intervening, with less than half (43\%) being comfortable with intervening in forest ecosystems. At the same time, they demonstrated a moderate interest in adopting more aggressive policies to save bristlecone pines if current interventions were shown to be failing. If policies after 10 years were doing well, only $36 \%$ of respondents were willing to change strategies, whereas if policies were definitely failing, just less than half of the participants were willing to try a more intensive approach in order to increase the likelihood of saving the bristlecone pines.

Transformative interventions (the lower right quadrant of Fig. 5) and, to a lesser degree, active interventions (the upper right quadrant of Fig. 5), represent the two management options with the highest intensity of human interference. As expected, higher proportions of respondents who preferred these strategies were also comfortable with intervening in forest ecosystems (59\% and 56\%, respectively); this willingness to support more intensive approaches to forest ecosystem management is supported by regression results (positive effect of the perceived importance of forests index). However, respondents who associate themselves with these two management options are at opposite ends of the spectrum in terms of their desire to conserve bristlecone pine.

Active intervention - the assisted migration (or assisted gene flow) of bristlecone pines that have genetic traits most needed for survival (aka assisted gene flow; Aitken and Whitlock 
2013) - is the option allocating the largest amount of effort towards conserving the bristlecone pine. Those favouring active intervention ( $27 \%$ of respondents), such as introducing pines with genetic traits that are thought to aid survival under the emerging climate regime, were comfortable with this choice and generally willing to take on somewhat higher levels of risk (e.g., assisted migration, but within the normal range of the species). This was particularly true if shown that the policies were needed due to the impacts of climate change. Similar proportions of respondents were willing to change strategies if after 10 years things were going well (37\%) as compared to definitely failing (35\%).

The segment of respondents favouring transformative interventions was the smallest of the four self-rated groupings (12\%); this may in part represent the non-linear nature of the strategies included in each of the four categories, with transformative intervention perhaps viewed as a significant jump in the intensity of management response compared to the difference between active and conventional interventions. Respondents supporting this strategy valued forest ecosystem functioning and, although tolerant of the challenges and risks associated with intervening to save an endangered species such as the bristlecone pine, accepted that survival of the bristlecone pine may not be possible. Such objective setting by triage approaches (Bottrill et al. 2008) are controversial in the conservation community (Knight et al. 2019) and may have been viewed as unacceptable by our respondents, particularly in light of the iconic status of the bristlecone pine. If bristlecone pine were shown to be doing well after 10 years, a large proportion (69\%) of the respondents in this highly adaptive group preferred to shift to a less intensive intervention strategy, whereas just over one-half chose to shift management approaches if the transformative intervention approach were shown to be failing. In contrast to the results for the non-interventionist group, lower levels of comfort with the initial choice of this intervention strategy seem to be inversely related to a greater the willingness to explore other types of interventions.

This empirical study also provides insights into how potential climate-adaptive conservation measures are best communicated to the public by scientists, resource managers, and policy makers (Boykoff 2019; Heller and Hobbs 2014; Kareiva and Fuller 2016). Results - as highlighted by the use of a decision-pathways survey approach — suggest that the efficacy of messaging is dependent on an individual's original stance as to what intervention they originally prefer and their comfort levels with intervening in the management of forest ecosystems more broadly. Those who originally opt for non-intervention (essentially, a "do nothing" stance) are less willing to intervene further, irrespective of messaging and the strength of future nudges. Respondents at the other extreme, having initially opted for a transformative intervention strategy, are much more willing to explore other interventions. Overall, individuals who characterize their initial position as either favouring transformative interventions or, to a lesser degree, active interventions are more labile in their views and more willing to shift both perceptions and the choice of a favoured management strategy on the basis of new information. Responses regarding respondents' level of comfort with their selection of a management policy do not show a consistent trend with the exception of those at the two extremes of the sample. For the minority favouring non-intervention, as comfort levels decrease, so too does their willingness to accept other interventions-this group appears more set in their ways and less willing to entertain new ideas. For the even smaller segment favouring transformative interventions, as comfort levels decrease their willingness to accept other interventions also increases-this group shows a greater willingness to consider and select alternative ways of intervening. 
The efficacy of the different climate change messaging provided to our respondents-a more rapid than expected decline in bristlecone pine populations, a decline in economic and social benefits associated with tourism and recreation, the species' (in)ability to adapt to natural disturbances, and a more severe than expected impact of climate change - also varied across the proposed management alternatives. Overall, messages about the severity of climate change appear to have the most impact, whereas (somewhat surprisingly) messages regarding declines in socio-economic benefits are least effective - a similar result is also highlighted in a recent study on assisted migration in British Columbia (Findlater et al. 2020). As a general observation, individuals who opted for transformative interventions were more likely to be adaptive and change their minds in response to positive messaging, whereas individuals who opted for conventional interventions respond more strongly to negative messaging. For individuals who initially selected conventional intervention (slightly less than one-half of the entire sample), the "loss is faster than expected" message was also compelling.

Collectively, these results present a challenge because they suggest that no single message is likely to have the intended effect of encouraging people to consider new information (Fischhoff and Scheufele 2013). This underscores the need for targeted communications and implies that the task of encouraging more informed, evidencebased forest management deliberations regarding a range of climate change adaptation strategies will remain difficult to the extent that questions regarding individual preferences for various conservation policies may need to be fine-tuned to reflect the language and specific concerns of stakeholders, as well as their broader social and political context. These differences are likely to be most pronounced at the extremes of the intervention choices (do nothing vs. transformative). However, our four-way division of respondents could, in part, represent an artefact of the pathways survey design. It might be helpful, for example, to separate conventional intervention into two categories in light of the relatively high percentage selecting this alternative. It might also be helpful to introduce another level of intervention at the high-intensity end that would pursue conservation of the bristlecone pine, for instance by proposing assisted migration of the species into entirely new areas (Butt et al. 2020; Dumroese et al. 2015), in contrast to transformative interventions, which fundamentally relinquish conservation efforts.

The earlier discussion of preference construction underscores a final point: scepticism should accompany interpretation of the publics' responses to online survey questions regarding climate change policies about which they may be unfamiliar. It also is possible that, in light of the novelty of the choices they are asked to make, respondents may look to the labels on each approach and simply find it less stressful to favour what we term a conventional intervention strategy. With these concerns in mind, results from a more interactive, openly deliberative inperson elicitation forum could be helpful to investigate how people respond to a similar set of questions regarding forest managers' options for protection of endangered species in light of the threats posed by climate change (McDaniels et al. 2012). Dialogue among group members would allow for clarifying questions to be asked over a period of time (e.g., several hours or days) and permit a more in-depth review of the role of uncertainty with respect to the consequences of management actions (Millar et al. 2007). What is learned in more interactive forums could also provide resource managers with valuable information about how to best facilitate a more adaptive mindset and encourage shifts in preferred management strategies as new information becomes available regarding the pros and cons of different climate-adaptive interventions. 
Supplementary Information The online version contains supplementary material available at https://doi.org/ 10.1007/s10584-021-03102-3.

Acknowledgements We thank three anonymous reviewers for their helpful comments.

Funding This work was financially supported by a grant from the Social Sciences and Humanities Research Council, SSHRC (Novel environmental management interventions in the Anthropocene -435-2017-0263), to SH at the University of British Columbia.

Data availability We have conducted our study following the BREB guidelines (Behavioral Research Ethics Board) at the University of British Columbia, Canada (Ethics ID number H17-01559). It is BREB's position that a breach of confidentiality of study participants has taken place when there is a failure to conform to the commitment that the researchers have made to the study participants when some or all the data has entered the public domain (i.e., the data has become available to any person who is not authorized to view or access the data). Thus, we shall not publicly disclose the raw research data in its original form. However, if readers are interested in requesting the raw dataset from this publication, they can contact the lead authors, and data can be shared upon request. They must sign a non-disclosure agreement and comply with the BREB's guidelines for further use of the data. Readers may contact shannon.hagerman@ubc.ca if they want to request data.

\section{References}

Aitken SN, Whitlock MC (2013) Assisted gene flow to facilitate local adaptation to climate change. Annu Rev Ecol Evol Syst 44:367-388

Aubin I, Garbe CM, Colombo S, Drever CR, McKenney DW, Messier C, Pedlar J, Saner MA, Venier L, Wellstead AM, Winder R, Witten E, Ste-Marie C (2011) Why we disagree about assisted migration: ethical implications of a key debate regarding the future of Canada\&apos;s forests. For Chron 87:755-765

Bottrill MC, Joseph LN, Carwardine J, Bode M, Cook C, Game ET, Grantham H, Kark S, Linke S, McDonaldMadden E, Pressey RL, Walker S, Wilson KA, Possingham HP (2008) Is conservation triage just smart decision making? Trends Ecol Evol 23:649-654

Boykoff M (2019) Creative (climate) communications: productive pathways for science, policy and society. Cambridge University Press, Cambridge

Brest P, Krieger LH (2010) Problem solving, decision making, and professional judgment: a guide for lawyers and policymakers. Oxford University Pres, Oxford

Butt N, Chauvenet ALM, Adams VM, Beger M, Gallagher RV, Shanahan DF, Ward M, Watson JEM, Possingham HP (2020) Importance of species translocations under rapid climate change. Conserv Biol 1:52

Colloff MJ, Lavorel S, van Kerkhoff LE, Wyborn CA, Fazey I, Gorddard R, Mace GM, Foden WB, Dunlop M, Prentice IC, Crowley J, Leadley P, Degeorges P (2017a) Transforming conservation science and practice for a postnormal world. Conserv Biol 31:1008-1017

Colloff MJ, Martín-López B, Lavorel S, Locatelli B, Gorddard R, Longaretti P-Y, Walters G, van Kerkhoff L, Wyborn C, Coreau A, Wise RM, Dunlop M, Degeorges P, Grantham H, Overton IC, Williams RD, Doherty MD, Capon T, Sanderson T, Murphy HT (2017b) An integrative research framework for enabling transformative adaptation. Environ Sci Pol 68:87-96

Corlett RT (2016) Restoration, reintroduction, and rewilding in a changing world. Trends Ecol Evol 31:453-462

Corner A, Parkhill K, Pidgeon N, Vaughan NE (2013) Messing with nature? Exploring public perceptions of geoengineering in the UK. Glob Environ Change 23:938-947

Corner A, Markowitz E, Pidgeon N (2014) Public engagement with climate change: the role of human values. WIREs Climate Change 5:411-422

Dieckmann NF, Johnson BB, Gregory R, Mayorga M, Han PKJ, Slovic P (2017) Public perceptions of expert disagreement: bias and incompetence or a complex and random world? Public Underst Sci 26:325-338

Dietz T (2013) Bringing values and deliberation to science communication. Proc Natl Acad Sci U S A 110: $14081-14087$

Dumroese RK, Williams MI, Stanturf JA, Clair JBS (2015) Considerations for restoring temperate forests of tomorrow: forest restoration, assisted migration, and bioengineering. New For 46:947-964

Failing L, Gregory R, Higgins P (2013) Science, uncertainty, and values in ecological restoration: a case study in structured decision-making and adaptive management. Restor Ecol 21:422-430

Findlater KM, Peterson St-Laurent G, Hagerman S, Kozak R (2020) Surprisingly malleable public preferences for climate adaptation in forests. Environ Res Lett 15:034045-034012 
Fischhoff B (2007) Nonpersuasive communication about matters of greatest urgency: climate change. Environmental Science \& Technology 41:7204-7208

Fischhoff B, Scheufele DA (2013) The science of science communication. Proc Natl Acad Sci U S A 110: $14031-14032$

Flynn J, Slovic P, Mertz CK (1994) Gender, race, and perception of environmental health risks. Risk Analysis 14:1101-1108

Folke C, Hahn T, Olsson P, Norberg J (2005) Adaptive governance of social-ecological systems. Annu Rev Environ Resour 30:441-473

Garnett ST, Zander KK, Hagerman S, Satterfield TA, Meyerhoff J (2018) Social preferences for adaptation measures to conserve Australian birds threatened by climate change. Oryx 52:325-335

Gilovich T, Griffin D, Kahneman D (eds) (2002) Heuristics and biases: the psychology of intuitive judgment. Cambridge University Press, New York, p xvi 857-xvi, 857

Gregory R, Lichtenstein S, Slovic P (1993) Valuing environmental resources: a constructive approach. J Risk Uncertain 7:177-197

Gregory R, Flynn J, Johnson SM, Satterfield TA, Slovic P, Wagner R (1997) Decision-pathway surveys: a tool for resource managers. Land Econ 73:240-254

Gregory R, Failing L, Higgins P (2006) Adaptive management and environmental decision making: a case study application to water use planning. Ecol Econ 58:434-447

Gregory R, Arvai J, Gerber LR (2013) Structuring decisions for managing threatened and endangered species in a changing climate. Conserv Biol 27:1212-1221

Gregory R, Satterfield T, Hasell A (2016) Using decision pathway surveys to inform climate engineering policy choices. Proc Natl Acad Sci U S A 113:560-565

Gross JE, Woodley S, Welling LA, Watson JEM (eds) (2016) Adapting to climate change: guidance for protected area managers and planners. Best Practice Protected Area Guidelines Series No. 24. IUCN, Gland, p 129

Hagerman SM (2016) Governing adaptation across scales: hotspots and hesitancy in Pacific Northwest forests. Land Use Policy 52:306-315

Hagerman SM, Pelai R (2018) Responding to climate change in forest management: two decades of recommendations. Front Ecol Environ 16:579-587

Hagerman SM, Satterfield T (2013) Entangled judgments: expert preferences for adapting biodiversity conservation to climate change. J Environ Econ Manag 129:555-563

Hagerman SM, Satterfield T (2014) Agreed but not preferred: expert views on taboo options for biodiversity conservation, given climate change. Ecol Appl 24:548-559

Hagerman S, Dowlatabadi H, Satterfield T, McDaniels T (2010) Expert views on biodiversity conservation in an era of climate change. Glob Environ Change 20:192-207

Hällfors MH, Vaara EM, Hyvärinen M, Oksanen M, Schulman LE, Siipi H, Lehvävirta S (2014) Coming to terms with the concept of moving species threatened by climate change - a systematic review of the terminology and definitions. PLoS One 9:e102979-e102913

Hancock N, Gallagher R (2014) How ready are we to move species threatened from climate change? Insights into the assisted colonization debate from Australia. Austral Ecology 39:830-838

Hansen LJ, Hoffman JR (2011) Climate savvy: adapting conservation and resource management to a changing world. Island Press, Washington, DC

Heller NE, Hobbs RJ (2014) Development of a natural practice to adapt conservation goals to global change. Conserv Biol 28:696-704

Heller NE, Zavaleta ES (2009) Biodiversity management in the face of climate change: a review of 22 years of recommendations. Biol Conserv 142:14-32

Hobbs RJ, Higgs E, Harris JA (2009) Novel ecosystems: implications for conservation and restoration. Trends Ecol Evol 24:599-605

Hoegh-Guldberg O, Hughes L, McIntyre S, Lindenmayer DB, Parmesan C, Possingham HP, Thomas CD (2008) Assisted colonization and rapid climate change. Science 321:345-346

IPBES (2019) Global assessment report on biodiversity and ecosystem services of the intergovernmental sciencepolicy platform on biodiversity and ecosystem services. IPBES secretariat, Bonn

IPCC (2014) Climate Change 2014: Impacts, Adaptation, and Vulnerability. Part A: Global and Sectoral Aspects. Contribution of Working Group II to the Fifth Assessment Report of the Intergovernmental Panel on Climate Change. Cambridge University Press, Cambridge, UK

IPCC (2018) Global warming of $1.5^{\circ} \mathrm{C}$. An IPCC Special Report on the impacts of global warming of $1.5^{\circ} \mathrm{C}$ above pre-industrial levels and related global greenhouse gas emission pathways, in the context of strengthening the global response to the threat of climate change, sustainable development, and efforts to eradicate poverty 
Kahan DM, Braman D, Gastil J, Slovic P, Mertz CK (2007) Culture and identity-protective cognition: explaining the white-male effect in risk perception. J Empir Leg Stud 4:465-505

Kahneman D (2011) Thinking, fast and slow. Farrar, Straus and Giroux, New York

Kareiva P, Fuller E (2016) Beyond resilience: how to better prepare for the profound disruption of the Anthropocene. Global Policy 7:107-118

Keenan RJ (2015) Climate change impacts and adaptation in forest management: a review. Ann For Sci 72:145167

Knight AT, Cook CN, Redford KH, Biggs D, Romero C, Ortega-Argueta A, Norman CD, Parsons B, Reynolds M, Eoyang G, Keene M (2019) Improving conservation practice with principles and tools from systems thinking and evaluation. Sustain Sci 14:1531-1548

Kohl PA, Brossard D, Scheufele DA, Xenos MA (2019) Public views about editing genes in wildlife for conservation. Conserv Biol 33:1286-1295

Leonard TC, Thaler RH, Sunstein CR (2008) Nudge: improving decisions about health, wealth, and happiness. Constit Polit Econ 19:356-360

Lichtenstein S, Slovic P (eds) (2006) The construction of preference. Cambridge University Press, Cambridge

Mawdsley JR, O'Malley R, Ojima DS (2009) A review of climate-change adaptation strategies for wildlife management and biodiversity conservation. Conserv Biol 23:1080-1089

McDaniels T, Mills T, Gregory R, Ohlson D (2012) Using expert judgments to explore robust alternatives for forest management under climate change. Risk Anal 32:2098-2112

Meine C (2015) A letter to the editors: in defense of the relative wild. US, Chicago, pp 84-95

Millar CI, Stephenson NL, Stephens SL (2007) Climate change and forests of the future: managing in the face of uncertainty. Ecol Appl 17:2145-2151

Miller B, Soulé ME, Terborgh J (2014) 'New conservation' or surrender to development? Anim Conserv 17: 509-515

Morton O (2015) The planet remade: how geoengineering could change the world. Granta, London

Moser SC (2014) Communicating adaptation to climate change: the art and science of public engagement when climate change comes home. Wiley Interdiscip Rev Clim Chang 5:337-358

Oliver TH, Smithers RJ, Bailey S, Walmsley CA, Watts K (2012) A decision framework for considering climate change adaptation in biodiversity conservation planning. J Appl Ecol 49:1247-1255

Palmer C, Larson BMH (2014) Should we move the Whitebark Pine? Assisted Migration, Ethics and Global Environmental Change. Environmental Values 23

Park A, Talbot C (2012) Assisted migration: uncertainty, risk and opportunity. For Chron 88:412-419

Pedlar JH, McKenney DW, Aubin I, Beardmore T, Beaulieu J, Iverson L, O’Neill GA, Winder RS, Ste-Marie C (2012) Placing forestry in the assisted migration debate. Bioscience 62:835-842

Peterson St-Laurent G, Hagerman S, Kozak R (2018) What risks matter? Public views about assisted migration and other climate-adaptive reforestation strategies. Clim Change 151:573-587

Peterson St-Laurent G, Hagerman SM, Kozak RA (In press-a) Cross-jurisdictional insights from practitioners on novel climate-adaptive options for Canada's forests. Reg Environ Chang

Peterson St-Laurent G, Oakes L, Cross M, Hagerman S (In press-b) R-R-T (resistance-resilience-transformation) typology reveals differential conservation approaches across ecosystems and time. Nature Communications Biology

Prober SM, Doerr VAJ, Broadhurst LM, Williams KJ, Dickson F (2019) Shifting the conservation paradigm: a synthesis of options for renovating nature under climate change. Ecol Monogr 89:e01333-e01323

Román-Palacios C, Wiens JJ (2020) Recent responses to climate change reveal the drivers of species extinction and survival. Proc Natl Acad Sci U S A 117:4211

Satterfield T, Gregory R (1998) Reconciling environmental values and pragmatic choices. Soc Nat Resour 11: 629-647

Satterfield T, Conti J, Harthorn BH, Pidgeon N, Pitts A (2012) Understanding shifting perceptions of nanotechnologies and their implications for policy dialogues about emerging technologies. Sci Public Policy 40:247260

Serrouya R, Seip DR, Hervieux D, McLellan BN, McNay RS, Steenweg R, Heard DC, Hebblewhite M, Gillingham M, Boutin S (2019) Saving endangered species using adaptive management. Proc Natl Acad Sci U S A 116:6181-6186

Shrum T, Markowitz E, Buck H, Gregory R, van der Linden S, Attar S, van Boven L (2020, in press) Behavioral frameworks to understand public perceptions of and risk response to carbon dioxide removal. J R Soc Interface

Slovic P (1997) Trust, emotion, sex, politics, and science: surveying the risk-assessment battlefield. In: Bazerman M, Messick D, Tenbrunsel S, Wade-Benzoni K (eds) Environment, Ethics and Behavior. New Lexington Press, San Francisco, CA, pp 277-313

Slovic P (2000) The perception of risk. Earthscan Publications, New York, NY 
Slovic P (2015) When (in)action speaks louder than words: confronting the collapse of humanit arian v alues in foreign policy decisions. Illinois Law Review Slip Opinions:24

Slovic P, Finucane M, Peters E, MacGregor DG (2002) The affect heuristic. Heuristics and biases: the psychology of intuitive judgment. Cambridge University Press, New York, pp 397-420

Sousa-Silva R, Ponette Q, Verheyen K, Van Herzele A, Muys B (2016) Adaptation of forest management to climate change as perceived by forest owners and managers in Belgium. Forest Ecosystems:1-11

Steel BS, List P, Shindler B (1994) Conflicting values about federal forests: a comparison of national and Oregon publics. Soc Nat Resour 7:137-153

Stein BA, Shaw MR (2013) Biodiversity conservation for a climate-altered future. In: Moser SC, Boykoff MT (eds) Successful adaptation to climate change: linking science and policy in a rapidly changing world. Routledge, Milton Park, pp 50-66

Stritch L, Mahalovich M, Nelson KG (2011) Pinus longaeva. The IUCN Red List of Threatened Species 2011: e.T34024A9830878.1-13

Tam J, McDaniels TL (2013) Understanding individual risk perceptions and preferences for climate change adaptations in biological conservation. ENVIRONMENTAL SCIENCE \& POLICY 27:114-123

Walters CJE (1986) Adaptive management of renewable resources. Collier Macmillan, London

Walters C (1997) Challenges in adaptive management of riparian and coastal ecosystems. Conserv Ecol 1

Publisher's note Springer Nature remains neutral with regard to jurisdictional claims in published maps and institutional affiliations. 